\title{
EFFICIENCY OF BIOMETRIC RECOGNITION TECHNOLOGY BASED ON TYPING DYNAMICS IN MOOC
}

\author{
Dr. Manuel MEDINA-LABRADOR \\ ORCID 0000-0001-6781-9481 \\ Faculty of Psychology, University Konrad Lorenz \\ Bogota, COLOMBIA \\ Dr. Marcela Georgina GOMEZ-ZERMENO \\ ORCID 0000-0002-5427-2891 \\ Tecnologico de Monterrey, Campus Monterrey \\ Monterrey, MEXICO \\ Dr. Lorena ALEMAN DE LA GARZA \\ ORCID 0000-0001-8567-0908 \\ Tecnologico de Monterrey, Campus Monterrey \\ Monterrey, MEXICO
}

Received: 10/07/2019 Accepted: 10/06/2020

\begin{abstract}
One of the problems that require a solution in Massive Open Online Courses (MOOC) is the lack of identification and authentication of the students. Different investigations have been carried out through several navigation, physiological and behavioral methods, achieving different recognition scales. Biometric authentication by keystroke patterns (Ups\&Downs) has been implemented in several MOOCs for the ease of the digital platforms of the offeror to solve the identification problem. The objective of this research is to analyze the independence of the keystroke tool of the other demographic, sociographic and behavioral variables within a MOOC, establishing an initial pattern, and two authentication measurements throughout the course. The results show that the keystroke is independent of the analyzed variables, and it is reliable to identify the students in qualitative tests with extension answers.
\end{abstract}

Keywords: Biometrics, identification, MOOC, pulsations

\section{INTRODUCTION}

Digital technology applied in education has changed teaching and learning methods. Its growth has been accelerated in the last decade and has managed to optimize variables such as time, location, content, interaction, and communication. The accessibility of digital platforms allows the integration of students of different age ranges, educational levels, motivations towards achievement and socio-cultural characteristics. Within this context, the Massive Online Open Course (MOOC) trend has become a learning model of the future allowing asynchronously relating two learning factors such as the teacher and the student. The MOOCs optimize variables such as: tuition costs, time availability, previous requirements, student coverage and flexibility (Gutl, Rizzardini, Chang \& Morales, 2014; Zambrano, Cano \& Presiga, 2017). Through MOOCs, universities and global institutions are responsible for offering and promoting courses so that people can access without restriction, creating opportunities to democratize education (Fernandez-Ferrer, 2017).

Vilar et al. (2013) affirm that the information and communication technology (ICT) has triggered innovation processes in online education and dizzying changes driven by the demands of the Information Society and increasingly globalized work contexts, which focus on the modernization of processes training of future professionals. Franco-Casamitjana (2005); Franco-Casamitjana, et al., 2013 also confirm that the strategies that educational institutions use to bring knowledge closer to citizens will determine the limits of future 
learning networks. This education and continuous training have always been tools for the creation of wealth, and nowadays, in societies based on the information and technology economy, these factors acquire greater importance. Some experts predict that MOOCs will mutate into new forms that have a greater emphasis on the accompaniment of learning, so that progressively there will be a decrease in the number of participants and better accompaniment. Assessment systems will be implemented that guarantee the acquisition of competences and not only knowledge, and quality criteria will be established that do not limit themselves to issuing an assessment based on the "reputation" of the educational institution that offers the course, its terminal efficiency and / or dropout rate (Menendez, 2013).

The quality of a MOOC is a fundamental aspect that must be taken into account in the design and delivery; it is a key question if it is intended to offer through MOOCs, valuable learning experiences that can be sustainable in the long term. Therefore, the institutional quality audit has to contribute to the promotion of a high quality improvement in teaching and learning (EFQUEL, 2013). MOOCs must apply the same quality requirements that training courses offered online and at distance apply. The application of these quality criteria would provide an educational guarantee, provided that these indicators do not operate in isolation and are articulated in an appropriate way to have a comprehensive image of the reference educational system (Bernal et al., 2013). AlemAn de la Garza, Sancho and Gomez Zermeno (2015) corroborate that the fact that MOOCs are massive, online and open courses, requires greater rigor in the control of their quality, since these courses are aimed at different profiles, without much control of its results and achievement of its objectives. For this reason, the construction of identity verification tools should also strengthen quality in the key processes of a MOOC: planning, design, development and implementation.

However, the disadvantages of the MOOC question the recognition of the identity of the student, to certify that the person receiving the learning and performing the evaluations is who claims to be (Sanna \& Marciales, 2017). In this regard, the use of digital technology has allowed automate and improve these processes of biometric recognition, so that they have many applications and purposes, especially those related to security. Biometrics is a method of recognizing people based on their physiological or behavioral characteristics. It is a process similar to that usually performed by human beings recognizing and identifying their congeners by their physical appearance, their voice, their way of walking, among others. Biometric technologies are defined as automatic methods used to recognize people based on the analysis of their physical or behavioral characteristics. Depending on the biometric technique used, the parameters considered are different: grooves of the fingerprint, the geometry of the hand, voice, and facial image. From these parameters, a unique personal pattern is extracted, which will be the one used for later comparisons (Tapiador, 2005; INCIBE, 2016).

\section{Types of Biometric Technologies}

Learning management systems offer tools based on biometric technologies, which are usually applied in two phases: registration and authentication. Similarly, there are three modes used for the authentication of a person: physical element, knowledge of secret information, and biometrics. The physical element refers to the position of a key, smart card or digital passport. The knowledge of secret information is composed of an alphabetic, numeric or mixed password. Biometrics measures unique human characteristics or traits (Ali, Monaco, Tappert \& Qiu, 2015). In the case of MOOCs, it is not only necessary to identify the student at the time of registration, but also in the development of the course, especially when making qualitative answers. There are different technologies for the administration and identification of students of a MOOC.

Currently, biometric technologies are applied in three different areas: (a) Learning management system (LMS), (b) Mobile applications and (c) proprietary software. LMS (Learning Management System) focuses on the management of students, experiences during learning, and optimizes the time to create and distribute the courses with participants. Mobile applications allow students to manage and profile through different mobile systems such as tablets and smartphones. The proprietary software is developed by the course providers to create their learning platform and allows the inclusion of private biometric identification tools. The three student management technologies require to know with certainty that the students really did the academic tasks with qualitative answers assigned and that the selected tool achieves the objective of identification independently of the demographic characteristics of the students, technological tools of interrelation and that has sufficient reliability within the operating environment (Fenu, Marras \& Boratto, 2017). 
The biometric characteristics consider three features: physiological (retina, iris, facial or hand geometry), navigation (touch and mouse movements) and behavioral (signature, voice and dynamics in the keystrokes when writing) (Fenu, Marras \& Boratto, 2017). These characteristics are difficult to reproduce and cannot be lost or forgotten. Monaco, Stewart, Cha and Tapper (2013) have studied identification through facial recognition; the results indicate that they were able to identify the students in real time, at low process costs and with a high degree of confidence. The characteristic of the voice was used to identify the presence of other subjects with the student while doing the learning or evaluative activity (Roth, Liu, Ross \& Metaxas, 2013). Based on the dynamics of the keystroke, Monaco et al., (2013) incorporated the concept of stylometry, as linguistic characteristics that depend only on the syntax and hermeneutics of each subject.

\section{Biometric Verification by Pulsations}

Based on Monrose and Rubin (2000), the identification through the keystrokes, focuses on the student's writing style, contrasting a habitual typographic rhythm pattern, through one or more subsequent monitoring. Within the pulsations, two identification techniques are evident: static and continuous. The static technique makes the study within a certain time interval, and the continuous technique is carried out during the interaction. The continuous technique allows involving variables such as fatigue and attention, which normally appear within the process of student interaction. According to Deutshmann and Lindholm (2013) the continuous authentication systems consist of four parts: (1) Compilation of behavioral data gathered from the use of the mouse to the keyboard data (2) Classification of writing features, in different categories such as Ups and Downs, as their rate of change (3) Storage of the user profile and (4) Verification evaluation between the master profile and the digital behavior. In general, tactile capture algorithms include different gross gestures (time, manipulation, vibration, rotation, pressure, touch size and position) (Fenu, Marras \& Boratto, 2017; Hernandez-Ortega et al., 2020).

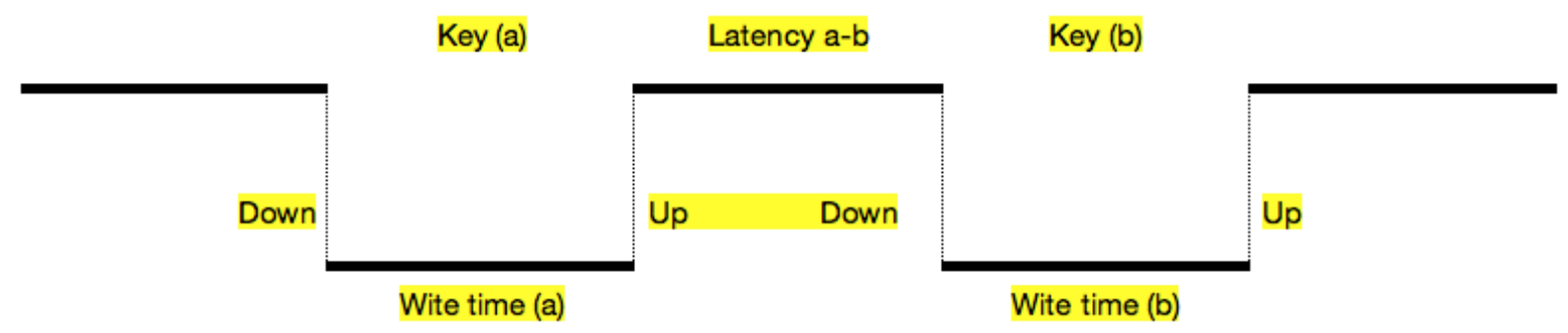

Figure 1. Biometric recognition technology based on the typing dynamics exposed by Morales, Fierrez,Vera-Rodriguez and Ortega-Garcia (2015)

The main objective of this work is to know if the biometric measure, pressure, rise, and change between letters is independent of the variables presented in a digital course or is influenced by characteristics of the students and the experiences that a selected MOOC presents. To achieve the objectives of this research, was used the biometric recognition technology based on the typing dynamics exposed by Morales, Fierrez,VeraRodriguez and Ortega-Garcia (2015) (Figure 1). This keystroke dynamics technology analyzes and models the waiting time or time of pressing and releasing a key and the time of elevation or difference between the type of key pressed and the time of elevation of the previous key, through a sequence according to the number of characters the words have. Finally, a unique vector is determined for each individual that is related to the identity of the subject, this vector is stored as a template to be compared later between the moment of registration and the moment of evaluative cuts.

\section{METHOD}

In a world that generates large amounts of data, the mathematics applied in its analysis can replace some traditional research instruments. For Siemens (2011), education brings together a surprising variety of quantitative data in teaching-learning processes, which have been little used. For this reason, online 
education institutions have recently begun to study how to apply data analytics to understand and design new metrics to assess learning (Aleman de la Garza, 2019; Aleman de la Garza y Gomez Zermeno, 2019).

Cross (2013) reports that MOOC research generates new methodological and interpretive challenges. It warns of the difficulty of adequately coding and analyzing a large amount of information from disparate sources to determine how and on what terms the success of a course is valued. This type of analysis can be complicated, because the public is massive and heterogeneous, the particular uses, and the articulations of technologies with pedagogy in a MOOC context, still need to be tested with appropriate instruments (AlemAn, 2019, VelAzquez Sortino, et al., 2017).

This research presents a transactional and longitudinal quantitative analysis based on students of a MOOC during the first semester of 2018. Two stages were conducted: Stage 1, Descriptivo, Stage 2, Relational and Stage 3, Predictive. Confirmation of the identification of the subject was chosen as a dependent variable during two moments. The analyzes were performed with the IBM SPSS Statistics program version 25 . To examine the results and find the independence of the Software regarding the way students are identified based on their writing profile, the independent variables used were: gender, age, educational level, amount of data lost at the time of registration, interest for the certificate, participation in the forum, participation in peer evaluation, enrollment status and identification of the subject at the time of registration.

\section{Participants}

The population analyzed corresponds to the participants of a MOOC focused on Electrical Engineering $(\mathrm{N}=4.232)$. Those students under the age of 18 who preferred to perform the MOOC at their own pace were excluded from the study (outside of the stipulated dates for the planned activities), resulting 4.060 participants. The lost data of the participants at the time of registering presents an $\mathrm{M}=2.55$ and $\mathrm{SD}=.67$, failing to report their complete information. $85.5 \%$ of the participants were Mexican and the rest from different parts of the world in small proportions (Table 1).

Table 1. Demographic information of those registered in all MOOCs

\begin{tabular}{|c|c|}
\hline Gender & Female (23.6\%), Male (76.2\%) \\
\hline $\begin{array}{l}\text { Level of schooling } \\
\text { (years) }\end{array}$ & $8(0.1 \%), 10(41.1 \%), 12(22.4 \%), 14(5.5 \%), 16(19 \%), 18(1 \%), 22(8.5 \%)$, Lost $(0.3 \%)$, others $(2.1 \%)$. \\
\hline Rangos de edad & $\begin{array}{l}18 \text { a } 28(54.9 \%), 28 \text { a } 38(23.2 \%), 38 \text { a } 48(11.3 \%), 49 \text { a } 58(5.1 \%), 58 \text { a } 68(1.3 \%),>68(0.2 \%), \sin \\
\text { reportar }(4.1 \%) \text {. }\end{array}$ \\
\hline
\end{tabular}

\section{Instruments}

The students were recruited through digital advertising for a period of two months. The cost of the certificate was 50 USD and the duration of the course was five weeks. The students knew a unique start date, after which no other student could be linked. The MOOC used the Keytrack biometric identification software, which measured the agreement between the initial pattern (form b) and the measurements in percentages (form d). The analysis protocol followed three phases: (1) Registration, each student at the time of registration answered the question: What are the expectations you have about the course? This question served as a biometric pattern and did not the present time or character limits. (2) First-grade assessment, once week three arrived, students were presented with a qualitative question about the course material of block three. (3) Second-level assessment, at the end of the last week of the course, the students answered in an extensive way, a question about block five of the course. Both in the evaluation, a and b, the returns of the questions were recorded and contrasted against the pattern of phase one, to determine the concordance between the Ups and Downs on the keyboard, and the speeds between letters. 


\section{Data Collection and Analysis}

The data collection was done through four forms: (a) Registration form with the demographic characteristics of the students (gender, age, country, and educational level); (b) Initial Comment Form, which presented the different interests of the participants in carrying out the course qualitatively; (c) Interest to obtain the Certificate form, which contained the question about whether they wanted to buy the course approval diploma digitally; (d) Evaluation form for qualitative questions for biometric authentication. This form was applied in two different weeks of the MOOC. The use of the keyboard was mechanical, and in the case of laptops, their one was used.

\section{FINDINGS}

The analyses were carried out according to the stages and estimated phases and sought to provide an answer: (a) the percentages of identification in the first and second measurements, (b) the independence of biometrics recognition of independent variables and (c) the relationship between the two recognitions. For Stage 1, descriptive, recognition (a), had a participation of 225 students $(M=91.84, D S=23.83)$ and the software identified the pattern with the answers in $89.8 \%$ with a coincidence between $80-100 \%$. For recognition (b), 231 responses were received $(M=89.24, D S=24.95)$ and the software results were consistent with the initial pattern at $87 \%$, with a coincidence between the range $80-100 \%$ (Figure 2).

Within the development of Stage 2, Relational, the possible association between the independent variables (gender, educational level, age range, amount of data lost at the time of registration, participation in the forum, participation in peer evaluation and certificate eligibility) was analyzed with the recognition (a) and (b); to identify if any variable had an impact on the identification, or on the opposite, to know if the recognition of the student identity only depended on the comparison with the initial patterns. The results indicate that the recognitions (a) and (b) are independent of the selected variables (Table 2). Likewise, the week of student abandonment is not associated with biometric recognition, for the first identification $\mathrm{F}(20$, $\mathrm{N}=224)=1.54, \mathrm{p}=0.1$ and for the second $\mathrm{F}(20, \mathrm{~N}=230)=0.76, \mathrm{p}=0.5$.

Finally, the relationship between the two established biometric recognition was analyzed; were found associations between the identification percentage (80-100\%) of the instant one with the identification percentage $(80-100 \%)$ of the instant two; $\mathrm{F}(5, \mathrm{~N}=178)=1.40, \mathrm{p}=0.16$. The above values indicate that the same subjects were identified within a high range of identification in the two measurements, that their identification was not random and that the passage of time or experiences within the space of the measurements are not related; on the contrary, they are independent.

$O=$ Recognition one

Recognition two

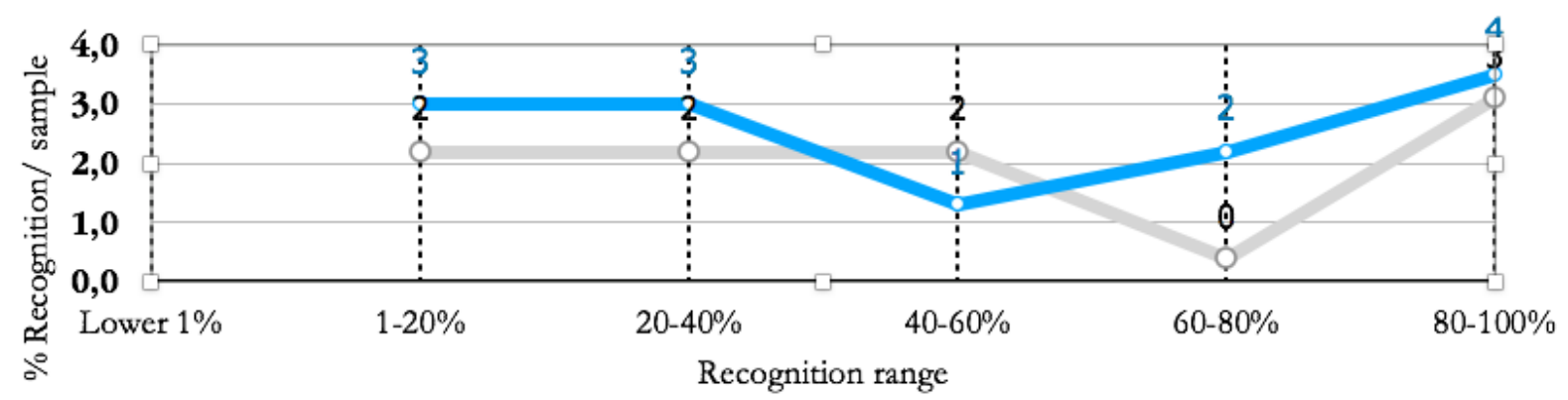

Figure 2. Percentage of recognition by sampling 
Table 2. Independence of recognition of student identity

\begin{tabular}{ccc}
\hline \multirow{2}{*}{ Independent variable } & \multicolumn{2}{c}{ Value of the test } \\
\cline { 2 - 3 } & $\mathrm{X} 2(4, \mathrm{~N}=224)=3.25, \mathrm{p}=0.6$ & $\mathrm{X} 2(4, \mathrm{~N}=230)=2.94, \mathrm{p}=0.7$ \\
Gender & $\mathrm{X} 2(30, \mathrm{~N}=225)=28.97, \mathrm{p}=0.7$ & $\mathrm{X} 2(30, \mathrm{~N}=231)=27.79, \mathrm{p}=0.8$ \\
Educational level & $\mathrm{F}(5, \mathrm{~N}=225)=0.50, \mathrm{p}=0.7$ & $\mathrm{~F}(5, \mathrm{~N}=225)=0.25, \mathrm{p}=0.9$ \\
Lost data & $\mathrm{X} 2(5, \mathrm{~N}=224)=2.88, \mathrm{p}=0.7$ & $\mathrm{X} 2(5, \mathrm{~N}=231)=4.58, \mathrm{p}=0.4$ \\
Participacion foro & $\mathrm{X}(20, \mathrm{~N}=224)=18.66, \mathrm{p}=0.5$ & $\mathrm{X} 2(20, \mathrm{~N}=231)=0.82, \mathrm{p}=0.7$ \\
Rango de edad & $\mathrm{X} 2(4, \mathrm{~N}=224)=3.25, \mathrm{p}=0.6$ & $\mathrm{X} 2(4, \mathrm{~N}=224)=3.25, \mathrm{p}=0.6$ \\
\hline
\end{tabular}

Source: Author's compilation. \% Recognition (1) week three and (2) week five.

Within the development of Stage 3, Predictive, the results of the binary logistic regression in block zero indicate that the probability of successful recognition of the subjects in a second measurement with a percentage greater than $60 \%$ is 97.3 . For block 1 of the model, the ROA statistical efficiency score indicates that there is a significant improvement in the occurrence of the categories of the dependent variable $\left(\chi^{2}(1\right.$, $\mathrm{N}=224)=33.49, \mathrm{p}<.001)$ if a predictor variable. The Naglekerke coefficient of $\mathrm{R}$ squared; shows that the proposed model explains $75.4 \%$ of the variance of the dependent variable when the subject identification variable is added at the time of enrollment. For the final analysis of the regression, block 1 indicates that there is a $99.5 \%$ probability of correctness in the result of the identification of the subject in the final stage, when the software has identified the subjects in the first measurement; indicating that the software has an identification improvement capacity. The Wald score for the tested model shows that the independent variable (first measure) contributes significantly to the prediction of the dependent variable (second measure) Wald $(1, \mathrm{~N}=224)=.0, \mathrm{p}<.001)$ and the results obtained from this model can be generalized to the population.

\section{DISCUSSIONS AND CONCLUSION}

This document explored the efficiency of the pulse identification tool in a MOOC. The results indicate that the Keytrack tool identified the participants in two different measurements between $80-100 \%$. The identifications were made in authentication scenarios independent of the text and in a multiple session environment such as that carried out by Morales, Fierrez, Vera-Rodriguez and Ortega-Garcia (2015). The identification in weeks three and four were autonomous in relation to the variables: gender, educational level, lost data, interest in the certificate, week of student desertion and age range; confirming the independent capacity of the algorithm in terms of measuring Ups and Downs and providing a human trait which is typing on the computer. This human trait is consistent with the line of research by. The work also showed that the two recognitions were related to each other with an average association, and the same subjects identified in the first measurement were identified in the last one. It is interesting to describe that regardless of the number of characters per words, the percentage of identification remains with low variation. These results allow establishing that the method and the biometric verification by pulsations (Keytrack), provides enough evidence to confirm the identification of students who take online programs.

The results obtained in this research are consistent with the results of Monrose \& Rubin (2000). The Keytrack tool was able to identify each student using the writing style and find a unique pattern according to the typographic rhythm. The tool used to classify the students writings into different categories of Ups and Downs (Deutshmann \& Lindholm, 2013; Morales, Fierrez, Vera-Rodriguez \& Ortega-Garcia, 2015). On the other hand, a special contribution of this work is to show the learning capacity of the tool, after having been able to register and identify a student in a preliminary measure. In conclusion, the first identification of the subjects, allows predicting the final identification of the subject and explains it in $75.4 \%$; There is a $99.5 \%$ probability of correct identification of a subject, if a first identification is made and there are very few additional variables to improve the final prediction. The high probability of identification found in this study exceeded the biometric recognition rate per click estimated by Morales et al., (2015) which was 
9.05\%. Likewise, the Keytrack tool was more efficient in identifying participants with 23 words on average per response, in contrast to the 500 words used in the Morales et al. (2015). If individuals are identified the first time, they are more likely to identify them with a higher probability of success in a second measurement; however, when the subjects do not participate in the second measurement, the probability of identification remains high at $97.3 \%$.

In future works, it would be interesting to expand the study of the identification tools, in different topics of MOOCs with different degrees of difficulty and to estimate whether the emotions that the students present when answering the evaluation questionnaires affect the writing rhythm. Furthermore, it may be pertinent to evaluate the effect of the identification tool on other types of devices such as tablets and cell phones; to generate a comparison with the keyboards of the computers. These analyzes can help the student identification process, increasing confidence, the use of open-ended questions and reducing review times by teachers. Finally, the identification tool could also be used from the moment the student enters the platform with their password and thus have a mandatory initial registration as the first measure to complete the identification pattern. This information may be useful for application in other MOOC activities, such as participating in discussion forums.

Achnowledgements: This work was partially supported by TEC- Monterrey Mexico

\section{BIODATA and CONTACT ADDRESSES of AUTHORS}

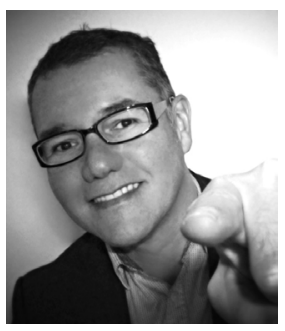

Prof.Dr. Manuel MEDINA-LABRADOR holds a Doctorate and a Master's degree in Consumer Psychology from Konrad Lorenz University in Colombia. He works as a Professor of Open and Distance Education at Virtual Education Faculty and Industrial Engineering Department, Pontificia Universidad Javeriana, BogotA. His academic interest areas are choice bias, acceptance and consumption of digital technology in business, university education, and professional training. He has worked as a teacher with the technique of MOOC, SPOOC and Podcast on issues related to the responsible increase in sales. He is a leading researcher in a digital marketing agency.

\section{Manuel MEDINA-LABRADOR}

Consumer Psychology, Faculty of Psychology, Konrad Lorenz University

Address: Carrera 9 Bis No. 62 - 43, BogotA, Colombia

Phone: +571 (3472311) ext. 119

E-mail: manuel_medina@icloud.com

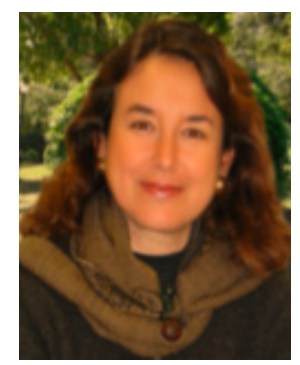

Prof.Dr. Marcela Gerogina GOMEZ-ZERMENO holds a Doctoral degree in Educational Innovation from Tecnologico de Monterrey, and a Master's in Information and Communication Technology Engineering Sciences INT-CITCOM, France Telecoms Higher Education. She also holds a Bachelor's in Computer and Administration Systems from ITESM. She is a research-professor at Tecnologico de Monterrey's master's degree programs in Education and in Educational Technology, as well as on the doctoral program in Educational Innovation. She is a member of the Mexican Education Research Council (COMIE). She is the technical manager on educational research projects of the Mexican National Council of Science and Technology (CONACYT) and on the ALFA program of the European Commission. She forms part of the National System of Researchers (SNI) Level 1.

\section{Marcela Gerogina GOMEZ-ZERMENO}

Tecnologico de Monterrey, Campus Monterrey

Ave. Eugenio Garza Sada, 2501 Sur, CP 64849 Monterrey, N.L., Mexico

Phone: +528116461430.

Email: marcela.gomez@tec.mx 
Prof.Dr. Lorena ALEMAN DE LA GARZA holds a Doctoral degree in Education

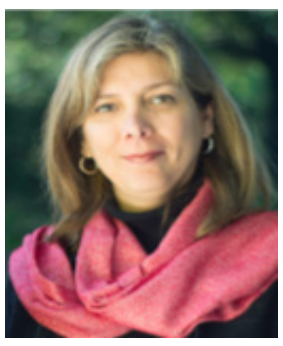
and ICT (e-learning) at the Open University of Catalonia (UOC), Spain. She holds a Master's degree, with Honors, in Educational Institution Administration from ITESM, and a Bachelor's degree, with Honors, in Business Administration from TecMilenio University, Mexico. She has worked as research-professor and postgraduate lecturer at Tecnologico de Monterrey's master's degree programs in Educational Institution Administration, in Education and in Educational Technology. She is the technical manager on educational research projects of the Mexican National Council of Science and Technology (CONACYT). She is also a professor at the Continuing Education at Tecnologico de Monterrey.

Lorena ALEMAN DE LA GARZA

Tecnologico de Monterrey, Campus Monterrey

Edificio Eugenio Garza Sada, 2501 Sur, CP 64849 Monterrey, N.L., Mexico

Phone: +528116461435

E-mail:

\section{REFERENCES}

Aleman de la Garza, L. (2019). Modelo de Indicadores de Calidad para Cursos En-Linea, Masivos y Abiertos (MOOC) "Caso de un MOOC para el desarrollo profesional docente". Mexico: Editorial Nomada. Consulted in https://repositorio.tec.mx/handle/11285/636171

AlemAn de la Garza, L., \& Gomez Zermeno, M. (2019). Analysis of the relation between teaching practices and academic performance. The International Journal of Assessment and Evaluation, 26(2): 1325. doi:10.18848/2327-7920/CGP/v26i02/13-25.

AlemAn, L.Y., Sancho-Vinuesa, T., y Gomez-Zermeno, M.G. (2015). Indicadores para evaluar la calidad de un curso en-linea masivo y abierto para la formacion continua. Revista Universidad y Sociedad del Conocimiento, 12(1), 104-118.

Ali, M.L., Monaco, J.V., Tappert, C.C. \& Qiu, M. Keystroke Biometric Systems for User Authentication. Journal of Signal Processing Systems, 86, 175-187. doi:10.1007/s11265-016-1114-9

Cross, S. (2013). Evaluation of the OLDS MOOC curriculum design course: participant perspectives, expectations and experiences. OLDS MOOC Project, Milton Keynes.

European Foundation for Quality in e-Learning (2013). The MOOC Quality Project. Recuperado de: http://mooc.efquel.org/the-mooc-quality-project/

Fenu, G., Marras, M., \& Boratto, L. (2018). A multi-biometric system for continuous student authentication in e-learning platforms. Pattern Recognition Letters, 113(9), 83-92. doi.org/10.1016/j. patrec.2017.03.027

FernAndez-Ferrer, M. (2017). Democratizando la educacion a nivel mundial: Ficcion o realidad? El papel de los cursos en linea masivos y abiertos. Revista profesorado.21(2), 445-457.

Franco-Casamitjana, M. (2005). ReseNa de "Sustaining the New Economy. Work, Family, and Community in the Information Age" de Martin Carnoy. Revista de Universidad y Sociedad del Conocimiento, 2(2). doi: http://dx.doi.org/10.7238/rusc.v2i2.255

Franco-Casamitjana, M., Barberà, E., y Romero, M. (2013). A Methodological Definition for Time Regulation Patterns and Learning Efficiency in Collaborative Learning Contexts. eLC Research Paper Series, 6, 52-62.

Gutl, C., Rizzardini, R. H., Chang, V., \& Morales, M. (2014). Attrition in MOOC: Lessons Learned from Drop- Out Students. In Learning Technology for Education in Cloud-MOOC and Big Data: Third International Workshop (Vol. 446, pp. 37-48). doi:10.1007/978-3-319-10671-7_4 
Hernandez-Ortega, J., Daza, R., Morales, A., Fierrez, J., Ortega-Garcia, J. (2020). edBB: Biometrics and Behavior for Assessing Remote Education. The AAAI 2019 Fall Symposium Series will be held in the fall of 2019 in Arlington, Virginia adjacent to Washington DC, USA. Consulted in https:// arxiv.org/pdf/1912.04786.pdf

INCIBE (2016). Tecnologias biometricas aplicadas a la ciberseguridad. Instituto Nacional de Ciberseguridad. Consulted in: https://www.incibe.es/protege-tu-empresa/guias/tecnologias-biometricas-aplicadasciberseguridad-guia-aproximacion-el

Menendez (2013). Estudiar 'online' y gratis. L A @, 80, 18-21. http://www.notariado.org/liferay/c/ document_library/get_file?folderId=12092\&name=DLFE-89971.pdf

Monaco, J.V., Stewart, J. C., Cha, S. H., \& Tappert, C. C. (2013, September). Behavioral biometric verification of student identity in online course assessment and authentication of authors in literary works. In 2013 IEEE Sixth International Conference on Biometrics: Theory, Applications and Systems (BTAS) (pp. 1-8). IEEE. Consulted in http://www.csis.pace.edu/ctappert/papers/2013BTAS.pdf

Monrose, F., \& Rubin, A. D. (2000). Keystroke dynamics as a biometric for authentication. Future Generation computer systems, 16(4), 351-359. doi: 10.1016/S0167-739X(99)00059-X

Morales, A., Fierrez, J., Vera-Rodriguez, R., \& Ortega-Garcia, J. (2016). Autenticacion Web de Estudiantes Mediante Reconocimiento Biometrico. III Congreso Internacional sobre Aprendizaje, Innovacion y Competitividad, (8), 365-370.

Roth, J., Liu, X., Ross, A., \& Metaxas, D. (2013, June). Biometric authentication via keystroke sound. In 2013 international conference on biometrics (ICB) (pp. 1-8). IEEE. Consulted in: https://www. cse.msu.edu/ -liuxm/publication/Roth_Liu_Ross_Metaxas_ICB2013.pdf

Sanna, P. \& Marcialis, G. (2017). Remote biometric verification for learning applications:where we are. In International Conference on Image Analysis and Processing (Vol. 10485, pp. 373-873). doi:10.1007/978-3-319-68548-9_35

Siemens, G., y Long, P. (2011). Penetrating the fog: Analytics in learning and education. Educause Review, 46(5).

Tapiador, M. (2005). Tecnologias Biometricas Aplicadas a la Seguridad", Madrid, EspaNa: Editorial Rama.

VelAzquez Sortino, M., Gomez Zermeno M. G. y Aleman de la Garza, L. (2017). Ic. Propuesta para un modelo de anAlisis. Digital Education Review, 31, 149-175

Vilar, R., C. Flores, C., Alvarez, J., Blasco, J., Grau, S., Navarro, I., Lledo, A., Lopez, E., Lorenzo, G., Martinez, M., Mengual, S., Mulero, J., Perandones, T., Rodriguez, C., Segura, A., Suarez, C., y Tortosa, M. (2013). Caracteristicas de los ambientes de aprendizaje online para una prActica docente de calidad. Indicadores de evaluacion. Presentado en las XI Jornadas de Redes de Investigacion en Docencia Universitaria. Alicante, EspaNa.

Zambrano, J., Cano, L., \& Presiga, K. (2017). Virtualidad y MOOC desde la perspectiva de estudiantes universitarios. Virtualidad, Educacion y Ciencia, 8(15), 106-119. Consulted in: https://revistas. unc.edu.ar/index.php/vesc/article/view/18961 